\title{
Influence of bentonite type and producing method on hydraulic conductivity of sand-bentonite mixture
}

\author{
Tomonori Sakita $^{1 *}$, Hideo Komine ${ }^{1}$, Atsuo Yamada ${ }^{2 *}$, Hailong Wang ${ }^{1}$, and Shigeru Goto ${ }^{1}$ \\ ${ }^{1}$ Waseda University, Japan \\ ${ }^{2}$ Hazama Ando Corporation, Japan
}

\begin{abstract}
Sand-bentonite mixtures with bentonite content of 10-30\% had been planned to handle low-level radioactive waste in Japan, because of its low permeability. Hydraulic conductivity of sand-bentonite mixture depends on the bentonite type, bentonite content, initial water content, and other factors. Given this background, falling head permeability tests were conducted on sand-bentonite mixture by varying the compaction energy for specimen preparation, initial water content (10-20\%), and bentonite content (15$30 \%$ ). For these tests, the hydraulic gradient of 25-500 was set. Consequently, the hydraulic conductivities were $10^{-8}-10^{-13} \mathrm{~m} / \mathrm{s}$ for all tested conditions. Correlation between the hydraulic conductivity and the effective montmorillonite dry density (montmorillonite mass divided by the sum of montmorillonite, air, water volume), which is often used to correlate the hydraulic conductivity of bentonite, was found. Correlation was also found between the hydraulic conductivity and a new index designated as the effective montmorillonite wet density (sum of montmorillonite and water mass / sum of montmorillonite, air, water volume). Effective montmorillonite wet density reveals differences in the specimen structural distribution through consideration of the initial water content.
\end{abstract}

\section{Introduction}

Sand-bentonite mixtures with bentonite contents of 10 $30 \%$ are slated as covering soil of waste to ensure low permeability and control groundwater flow in Japanese low-level radioactive waste disposal projects [1]. One planned disposal facility is a concrete pit facility, as presented schematically in Fig. 1.

At disposal facilities, the alkaline solution generated by leaching of cement-based material might cause bentonite deterioration, which might exert long-term effects on its low permeability. Therefore, understanding the alteration behaviour for the permeability of bentonite mixed soil is important. They must be predicted accurately to evaluate long-term nuclide migration in disposal facilities [2].

The various properties, including compaction characteristics and hydraulic conductivity of bentonite mixed soil are expected to differ depending on conditions such as the material mixing ratio, initial water content, mixing method, and water addition method [3]. These relations are important when planning the soil covering because they are the basis for material selection. However, few reports describe quality differences related to sample preparation and mixing methods. Falling head permeability test results are presented herein. The tests assess the effect of bentonite type, sand-bentonite content, specimen water content, and dry density. Meanwhile, the relationship between hydraulic conductivity and compaction characteristics is discussed.

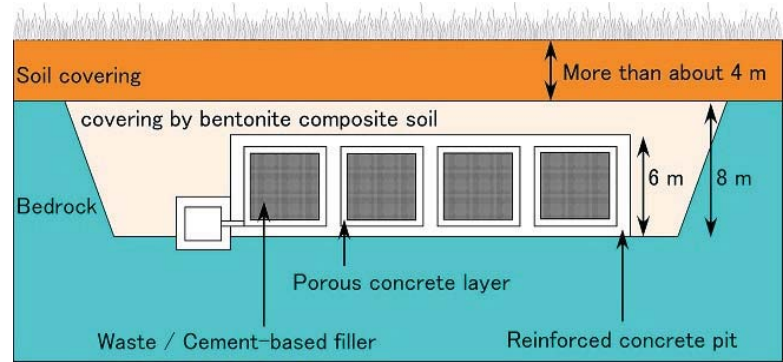

Fig. 1. Outline of concrete pit.

\section{Material, test method and program}

This section describes sample preparation details, an outline of conducted permeability tests, and experimental conditions.

\subsection{Material details}

Fine aggregate sand from Aomori Prefecture, Japan and Ca-type Kunibond bentonite from Kunimine Industries Co. Ltd, Japan were used in this study.

The sand particle density was $2.75 \mathrm{Mg} / \mathrm{m}^{3}$. Fig. 2 shows a sand grain size accumulation curve. Table 1 presents basic Ca-type bentonite properties. The montmorillonite content shown in Table 1 was calculated by comparing methylene blue adsorption of

\footnotetext{
* Corresponding author: tomonori127@asagi.waseda.jp
} 
this bentonite to of pure montmorillonite $(140 \mathrm{mmol} /$ $100 \mathrm{~g})$ [4].

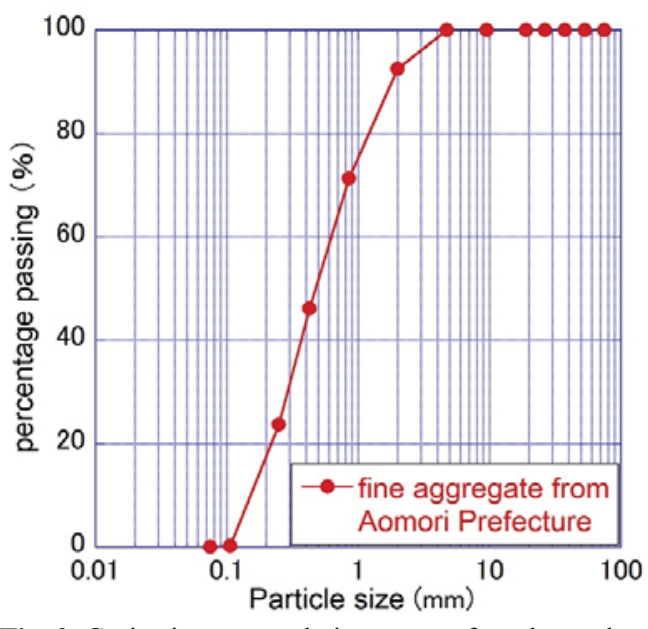

Fig. 2. Grain size accumulation curve of sand sample.

Table 1. Fundamental properties of Ca-type bentonite

\begin{tabular}{|c|c|}
\hline Kind of bentonite & Kunibond \\
\hline $\begin{array}{c}\text { Soil particle density } \\
\left(\mathrm{Mg} / \mathrm{m}^{3}\right)\end{array}$ & 2.63 \\
\hline Liquid limit (\%) & 124.8 \\
\hline Plastic limit (\%) & 55.9 \\
\hline Plasticity index & 68.8 \\
\hline $\begin{array}{c}\text { Montmorillonite } \\
\text { content (\%) }\end{array}$ & 71.4 \\
\hline
\end{tabular}

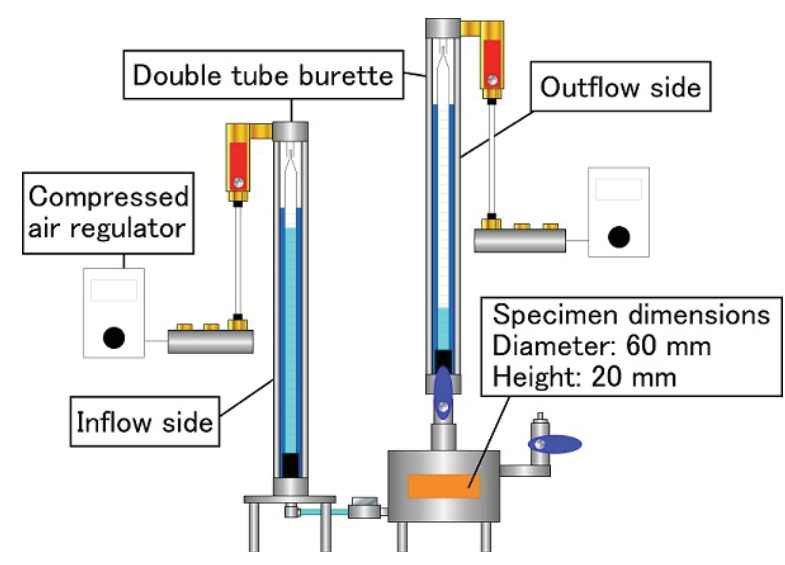

Fig. 3. Permeability test equipment.

\subsection{Outline and program of permeability test}

The bentonite mixed soil was adjusted using a mixer (1 $\mathrm{kg}$ input capacity, $300 \mathrm{rpm}$ stirring bar rotation speed). bentonite content to sand by dry mass ratio were 10
$30 \%$. The water content was adjusted in a range of 10 $20 \%$.

A permeability test device with a $60-\mathrm{mm}$ mold inner diameter and $20 \mathrm{~mm}$ height was used in this study, as depicted in Fig. 3. It was designed for using with falling head devices. Specimens were prepared by placing the soil mixture directly in the mold and compacting it in two layers. The specimen mass was calculated by equation (1) in order to prepare the specimen at any dry density.

$$
m=\rho_{d} \times V \times\left(1+\frac{w}{100}\right)
$$

Therein, $m$ denotes the specimen mass, $\rho_{d}$ expresses the dry density, $V$ signifies the specimen volume, and $w$ stands for the water content.

The specimens were compacted under respectively $1 \mathrm{Ec}$ and $4.5 \mathrm{Ec}$, and arbitrary, where arbitrary represents prepared by control specimen dry density rather than compaction energy. Fig. 4 presents the results of compaction curves of mixed soil with 30\% Ca-type bentonite content. In the case of controlling the compaction energy of the specimen, the mass of the specimen is set using the water content-dry density relationship shown in Fig. 4.

Specimen details in this study are shown in Table 2. Regarding specimen conditions, the bentonite content was 15,20 , or $30 \%$; the initial moisture content was 10 $20 \%$. The dry density was $1.5-2.0 \mathrm{Mg} / \mathrm{m}^{3}$.

After preparation, the specimen was installed in the apparatus and together with the apparatus submerged in a water tank for specimen saturation. Negative pressure of about $-0.1 \mathrm{MPa}$ was applied stepwise to the tank for one week. The mold, top lid and bottom plate were tightened to prevent volume expansion of the specimen during the during saturation process and permeability tests.

During the permeation process, the water flowed from the bottom surface to the top surface of the specimen. Air pressures of $110-200 \mathrm{kPa}$ at the inflow side and $100 \mathrm{kPa}$ at the outflow side of burettes were applied (Fig. 3), which correspond to a range of hydraulic gradient of 5-200.

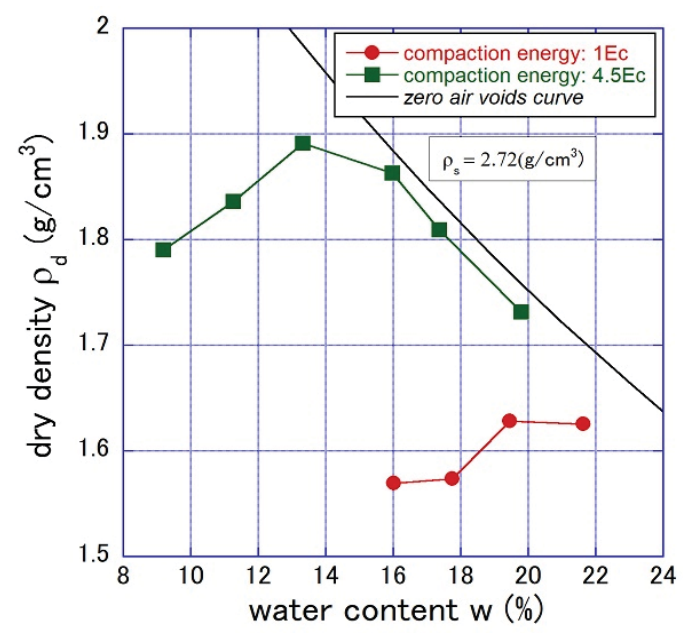

Fig. 4. Results of compaction tests of mixed soil with $30 \%$.Catype bentonite content. 
Table 2. Permeability test conditions

\begin{tabular}{|c|c|c|c|c|c|c|}
\hline $\begin{array}{c}\text { Compaction } \\
\text { energy }\end{array}$ & $\begin{array}{l}\text { Bentonite } \\
\text { content } \\
(\%)\end{array}$ & $\begin{array}{c}\text { Water } \\
\text { content } \\
(\%)\end{array}$ & $\begin{array}{c}\text { Dry } \\
\text { density } \\
\left(\mathrm{Mg} / \mathrm{m}^{3}\right)\end{array}$ & $\begin{array}{c}\text { Initial degree } \\
\text { of saturation } \\
(\%)\end{array}$ & $\begin{array}{c}\text { Effective } \\
\text { montmorillonite } \\
\text { density } \\
\left(\mathrm{Mg} / \mathrm{m}^{3}\right) \\
\end{array}$ & $\begin{array}{l}\text { Hydraulic } \\
\text { conductivity } \\
(\mathrm{m} / \mathrm{s})\end{array}$ \\
\hline $4.5 \mathrm{Ec}$ & 15 & 10.0 & 1.97 & 69.8 & 0.589 & $2.58 \times 10^{-08}$ \\
\hline $4.5 \mathrm{Ec}$ & 15 & 11.9 & 1.97 & 83.8 & 0.593 & $7.92 \times 10^{-12}$ \\
\hline $4.5 \mathrm{Ec}$ & 15 & 14.4 & 1.90 & 89.6 & 0.537 & $1.79 \times 10^{-11}$ \\
\hline $4.5 \mathrm{Ec}$ & 15 & 15.9 & 1.84 & 89.4 & 0.495 & $9.16 \times 10^{-11}$ \\
\hline $4.5 \mathrm{Ec}$ & 15 & 18.1 & 1.81 & 96.9 & 0.475 & $1.26 \times 10^{-10}$ \\
\hline $4.5 \mathrm{Ec}$ & 20 & 9.4 & 1.91 & 60.2 & 0.687 & $9.81 \times 10^{-09}$ \\
\hline $4.5 \mathrm{Ec}$ & 20 & 11.7 & 1.95 & 80.1 & 0.723 & $1.02 \times 10^{-10}$ \\
\hline $4.5 \mathrm{Ec}$ & 20 & 13.8 & 1.94 & 92.6 & 0.712 & $4.05 \times 10^{-12}$ \\
\hline $4.5 \mathrm{Ec}$ & 20 & 15.3 & 1.88 & 92.2 & 0.657 & $5.34 \times 10^{-12}$ \\
\hline $4.5 \mathrm{Ec}$ & 30 & 12.1 & 1.83 & 67.9 & 0.838 & $5.40 \times 10^{-12}$ \\
\hline $4.5 \mathrm{Ec}$ & 30 & 13.8 & 1.90 & 87.2 & 0.910 & $8.04 \times 10^{-13}$ \\
\hline $4.5 \mathrm{Ec}$ & 30 & 16.1 & 1.86 & 95.0 & 0.868 & $1.11 \times 10^{-12}$ \\
\hline $4.5 \mathrm{Ec}$ & 30 & 17.8 & 1.77 & 90.4 & 0.781 & $1.30 \times 10^{-12}$ \\
\hline $1 \mathrm{Ec}$ & 30 & 15.9 & 1.53 & 55.7 & 0.590 & $9.78 \times 10^{-08}$ \\
\hline $1 \mathrm{Ec}$ & 30 & 17.2 & 1.61 & 68.0 & 0.649 & $9.53 \times 10^{-09}$ \\
\hline $1 \mathrm{Ec}$ & 30 & 18.5 & 1.64 & 76.8 & 0.673 & $8.74 \times 10^{-09}$ \\
\hline $1 \mathrm{Ec}$ & 30 & 18.9 & 1.63 & 77.4 & 0.666 & $5.62 \times 10^{-08}$ \\
\hline Arbitrary & 30 & 9.3 & 1.76 & 46.2 & 0.771 & $6.64 \times 10^{-11}$ \\
\hline Arbitrary & 30 & 10.9 & 1.76 & 54.5 & 0.772 & $3.54 \times 10^{-10}$ \\
\hline Arbitrary & 30 & 12.8 & 1.76 & 63.5 & 0.769 & $1.52 \times 10^{-10}$ \\
\hline Arbitrary & 30 & 15.9 & 1.76 & 79.7 & 0.775 & $5.09 \times 10^{-12}$ \\
\hline Arbitrary & 30 & 18.5 & 1.76 & 92.2 & 0.770 & $1.82 \times 10^{-12}$ \\
\hline
\end{tabular}

\section{Test results}

Generally speaking, for soil materials, water flows through the gaps in soil skeleton. Therefore, indices such as dry density and void ratio might be used to correlate the hydraulic conductivity. By contrast, in the bentonite mixed soil, the montmorillonite in the bentonite swells and partially fills voids during specimen saturation. Accordingly, it is conceivable that the unfilled voids or space between montmorillonite layers become the water paths [5-6]. Therefore, the effective montmorillonite density $\left(\rho_{\mathrm{em}}\right)$ proposed in past researches is often used [7] to correlate hydraulic conductivity for bentonite sand mixture. The effective montmorillonite density was defined by Equation (2).

$$
. \rho_{e m}=\frac{m_{m}}{V_{a}+V_{w}+V_{m}}
$$

In Equation (2), $m_{m}$ represents the montmorillonite mass, $V_{a}$ denotes the pore air volume, $V_{w}$ is the pore water volume, and $V_{m}$ denotes the montmorillonite volume.
Fig. 5 and Fig. 6 present the relationship between hydraulic conductivity and the effective montmorillonite density. The effective montmorillonite density is the value at the time of specimen preparation. Fig. 5 presents data of compaction energy of $4.5 \mathrm{Ec}$. The legend shows the blending bentonite content. Fig. 6 portrays only those data with bentonite content of $30 \%$. The legend presents the compaction energy.

From Figs. 5 and 6, one can confirm that the effective montmorillonite density increases as the bentonite content and compaction energy increase. The hydraulic conductivity decreases concomitantly with increasing effective montmorillonite density. For data with particularly low initial water content, Fig. 5 also shows that the hydraulic conductivity is higher, in fact three orders of magnitude higher, than other test data, even at the same bentonite content.

Correlation between the hydraulic conductivity and the effective montmorillonite density shows data variation, suggesting that it may be inappropriate as an alternative index of the hydraulic conductivity.

\footnotetext{
* Corresponding author: tomonori127@asagi.waseda.jp
} 


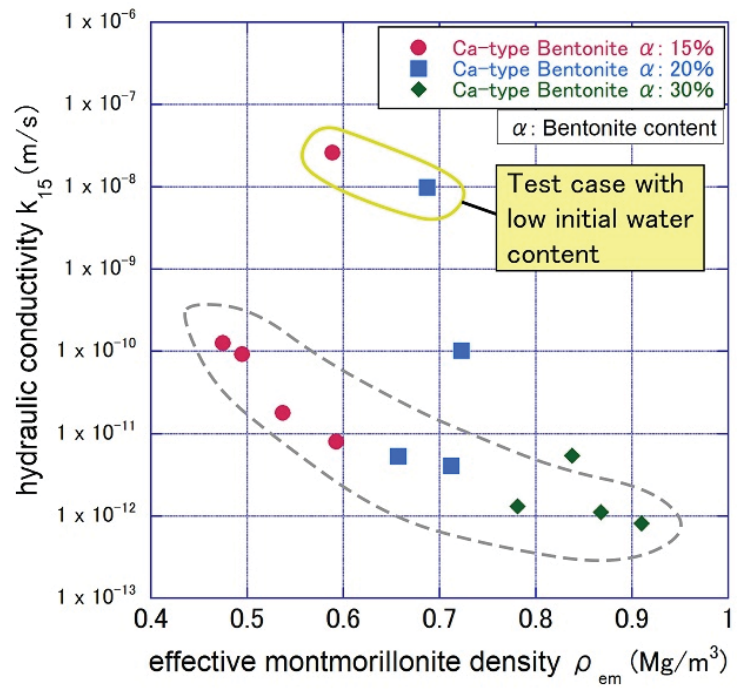

Fig. 5. Relation between hydraulic conductivity and effective montmorillonite density of Ca-type bentonite mixed soil compacted with $4.5 \mathrm{Ec}$ ( $\alpha$ in legend: bentonite content).

\section{Discussion}

The test results presented in Section 3 indicate that the effective montmorillonite density might not be an appropriate alternative index for the hydraulic conductivity of Ca-type bentonite mixed soil.

In this section, the effects of the initial water content and initial dry density of the specimen on the hydraulic conductivity of bentonite mixtures are inferred based on the studies by Tatsuoka et al [8] and Kitamura et al [9].

For two specimens with the same dry density at the time of specimen preparation but different initial water content, Fig. 7 portrays estimation of the effects of the difference in the initial water content on the permeability. According to results of former study [8] of clay and sand mixed soil specimens, specimens with low water content have strong matrix suction (the difference between pore air pressure and pore water pressure), thus leading clay particles aggregate around sand particles. By contrast, specimens with high water content have weak matrix suction. Clay particles are likely to be dispersed and distributed in voids. After specimen preparation, the bentonite absorbs water and swells during saturation, partially filling voids of specimens. We infer that the shape of the unfilled voids network depends on the distribution of bentonite particles during the specimen preparation. Fig. 7 shows that a large void is formed in a specimen with low water content, and that a small void is formed in a specimen with high water content. Larger voids in the specimen represents greater permeability, vice versa. Therefore, higher initial water content of the specimen is associated with lower hydraulic conductivity.

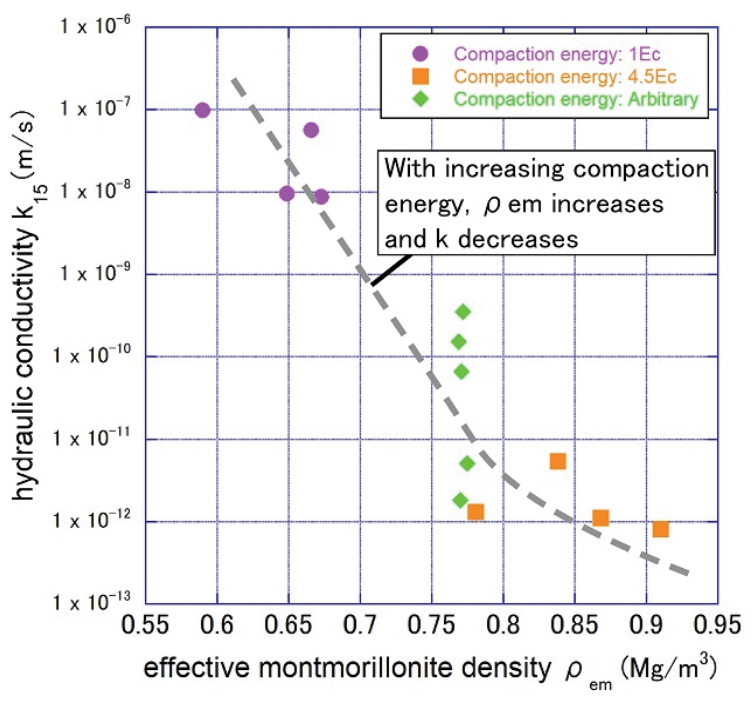

Fig. 6. Relation between hydraulic conductivity and effective montmorillonite density of Ca-type bentonite mixed soil with $30 \%$ bentonite content (legend: compaction energy).

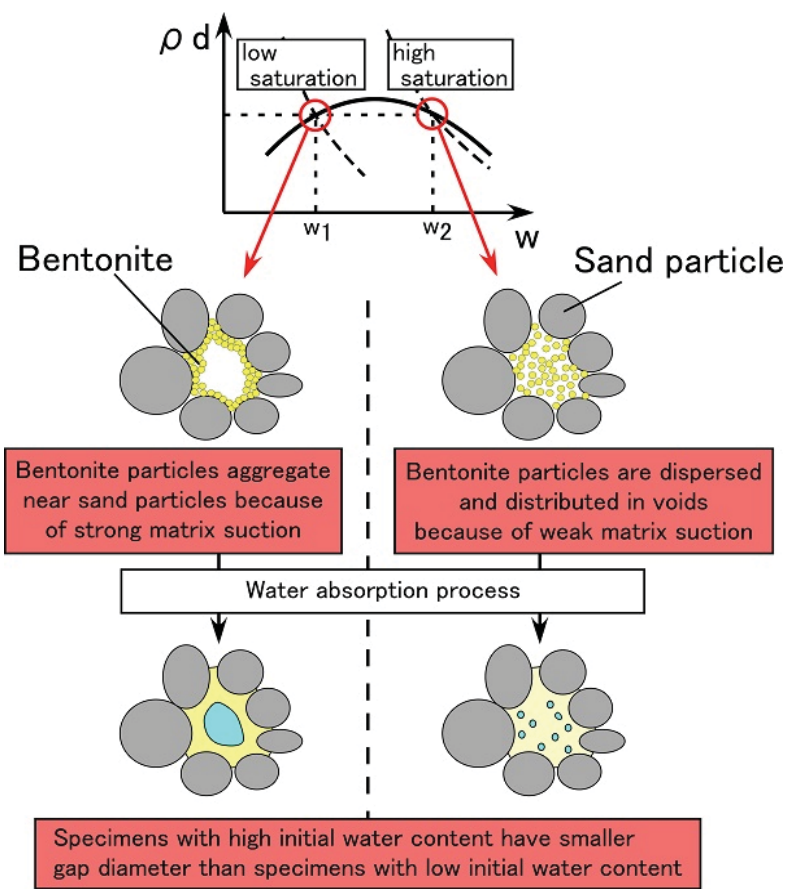

Fig. 7. Mechanism of the effect of initial moisture contents of specimens on the permeability

Next, Fig. 8 presents an estimation of the effects of differences in the initial dry density of the specimen on permeability. We consider conditions in which the initial water contents are equal, and conditions in which the dry density differs. The void ratio decreases as the dry density increases. Therefore, the voids volume in the specimen becomes smaller in a specimen with a higher dry density than in a specimen with a lower dry density. The voids volume in the specimen also decreases with swelling of the bentonite. 


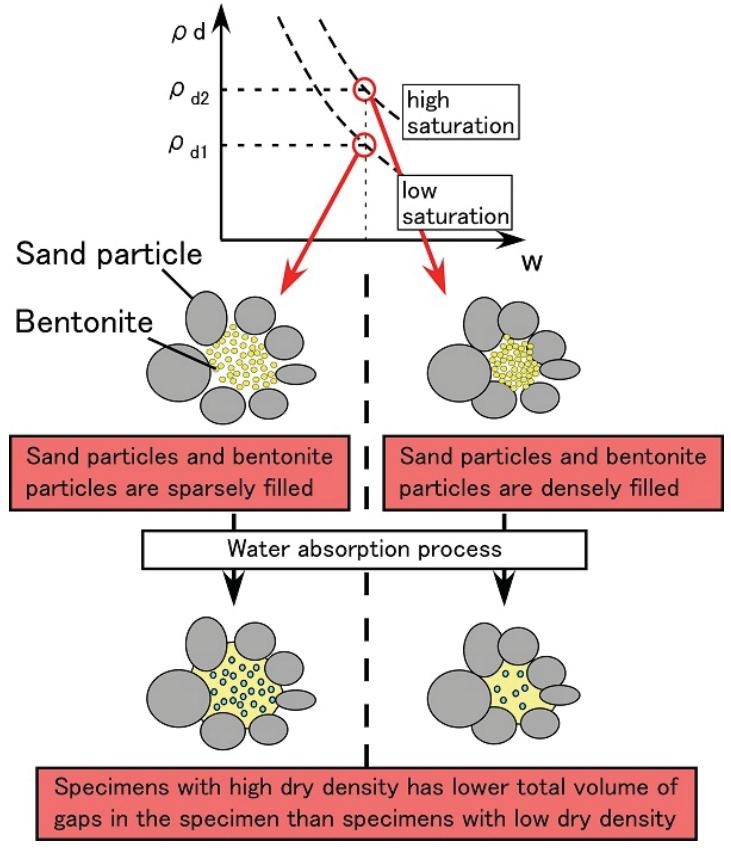

Fig. 8. Mechanism of the effects of the initial dry density of the specimen on the permeability

Based on these inferences described above, one might then infer greater initial water content and higher initial dry density, i.e., at higher initial saturation, more pores with small diameters are distributed in the specimen after saturation. Therefore, the voids volume is reduced. This inference then suggests that the initial saturation of the specimen is the dominant factor affecting the hydraulic conductivity of bentonite mixed soils.

Equation (3) shows that the effective montmorillonite density does not incorporate consideration of the mass of pore water in the specimen. As described above, because the initial water content of the specimen might affect hydraulic conductivity of bentonite-mixed soil, the pore water mass should be considered when applying the alternative index of hydraulic conductivity. Therefore, we propose the effective montmorillonite wet density defined by equation (3).

- effective montmorillonite wet density:

$$
\rho_{e m t}=\frac{m_{m}+m_{w}}{V_{a}+V_{w}+V_{m}}
$$

Therein $m_{m}$ stands for the montmorillonite mass, $m_{w}$ denotes the pore water mass, $V_{a}$ represents the pore air volume, $V_{w}$ expresses the pore water volume, and $V_{m}$ signifies the montmorillonite volume.

Fig. 9 and Fig. 10 show the relation between the hydraulic conductivity of Ca-type bentonite mixed soil and the effective montmorillonite density or effective montmorillonite wet density. The legend in each figure is the initial saturation range of the specimen. To clarify correlation between plots, the results are summarized together with the earlier results of permeability tests [3]. In these tests, materials used in the experiments are also fine aggregate sand from Aomori Prefecture, Japan and

Table 3. Permeability test conditions by [3]

\begin{tabular}{|c|c|c|c|}
\hline $\begin{array}{c}\text { Bentonite } \\
\text { content } \\
(\%) \\
\end{array}$ & $\begin{array}{c}\text { Initial water } \\
\text { content } \\
(\%)\end{array}$ & $\begin{array}{c}\text { Dry } \\
\text { density } \\
\left(\mathrm{Mg} / \mathrm{m}^{3}\right)\end{array}$ & $\begin{array}{c}\text { Hydraulic } \\
\text { conductivity } \\
(\mathrm{m} / \mathrm{s})\end{array}$ \\
\hline 20 & 9.0 & 1.86 & $9.34 \times 10^{-10}$ \\
\hline 20 & 13.0 & 1.90 & $3.39 \times 10^{-10}$ \\
\hline 20 & 15.0 & 1.87 & $7.17 \times 10^{-11}$ \\
\hline 20 & 17.0 & 1.83 & $2.55 \times 10^{-11}$ \\
\hline 20 & 19.0 & 1.76 & $5.46 \times 10^{-11}$ \\
\hline 20 & 13.0 & 1.81 & $5.61 \times 10^{-09}$ \\
\hline 20 & 15.0 & 1.78 & $2.58 \times 10^{-09}$ \\
\hline 20 & 17.0 & 1.74 & $1.14 \times 10^{-09}$ \\
\hline 20 & 19.0 & 1.67 & $1.27 \times 10^{-09}$ \\
\hline 30 & 12.2 & 1.74 & $9.39 \times 10^{-11}$ \\
\hline 30 & 16.2 & 1.80 & $2.65 \times 10^{-11}$ \\
\hline 30 & 18.2 & 1.77 & $1.01 \times 10^{-11}$ \\
\hline 30 & 20.2 & 1.70 & $2.14 \times 10^{-11}$ \\
\hline 30 & 22.2 & 1.65 & $1.64 \times 10^{-11}$ \\
\hline 30 & 16.2 & 1.71 & $5.24 \times 10^{-10}$ \\
\hline 30 & 18.2 & 1.68 & $2.38 \times 10^{-10}$ \\
\hline 30 & 20.2 & 1.61 & $3.76 \times 10^{-10}$ \\
\hline 30 & 22.2 & 1.57 & $4.15 \times 10^{-10}$ \\
\hline 40 & 15.0 & 1.60 & $2.40 \times 10^{-11}$ \\
\hline 40 & 19.0 & 1.67 & $1.44 \times 10^{-11}$ \\
\hline 40 & 21.0 & 1.64 & $1.00 \times 10^{-11}$ \\
\hline 40 & 23.0 & 1.62 & $4.90 \times 10^{-12}$ \\
\hline 40 & 25.0 & 1.58 & $4.70 \times 10^{-12}$ \\
\hline 40 & 19.0 & 1.58 & $9.96 \times 10^{-11}$ \\
\hline 40 & 21.0 & 1.56 & $1.60 \times 10^{-10}$ \\
\hline 40 & 23.0 & 1.54 & $1.68 \times 10^{-10}$ \\
\hline 40 & 25.0 & 1.50 & $1.10 \times 10^{-10}$ \\
\hline 30 & 12.0 & 1.68 & $2.17 \times 10^{-09}$ \\
\hline 30 & 16.0 & 1.75 & $1.46 \times 10^{-09}$ \\
\hline 30 & 20.0 & 1.71 & $2.60 \times 10^{-11}$ \\
\hline 30 & 11.0 & 1.73 & $1.13 \times 10^{-10}$ \\
\hline 30 & 15.0 & 1.81 & $2.50 \times 10^{-11}$ \\
\hline 30 & 17.0 & 1.79 & $1.17 \times 10^{-11}$ \\
\hline 30 & 19.0 & 1.77 & $2.31 \times 10^{-12}$ \\
\hline 30 & 19.0 & 1.68 & $8.42 \times 10^{-11}$ \\
\hline 30 & 19.0 & 1.56 & $3.40 \times 10^{-09}$ \\
\hline 30 & 17.0 & 1.70 & $1.12 \times 10^{-10}$ \\
\hline 30 & 19.0 & 1.68 & $5.85 \times 10^{-11}$ \\
\hline 15 & 8.4 & 1.88 & $9.27 \times 10^{-09}$ \\
\hline 15 & 12.4 & 1.95 & $1.25 \times 10^{-10}$ \\
\hline 15 & 14.4 & 1.90 & $2.68 \times 10^{-11}$ \\
\hline 15 & 16.4 & 1.83 & $7.44 \times 10^{-11}$ \\
\hline 15 & 14.4 & 1.81 & $4.77 \times 10^{-09}$ \\
\hline 15 & 16.4 & 1.74 & $2.28 \times 10^{-09}$ \\
\hline 30 & 11.0 & 1.73 & $1.24 \times 10^{-10}$ \\
\hline 30 & 15.0 & 1.81 & $1.11 \times 10^{-11}$ \\
\hline 30 & 17.0 & 1.79 & $8.90 \times 10^{-12}$ \\
\hline 30 & 19.0 & 1.77 & $1.52 \times 10^{-12}$ \\
\hline 30 & 17.0 & 1.70 & $8.15 \times 10^{-11}$ \\
\hline 30 & 19.0 & 1.68 & $3.74 \times 10^{-11}$ \\
\hline 30 & 20.0 & 1.68 & $5.86 \times 10^{-11}$ \\
\hline 30 & 20.0 & 1.68 & $2.61 \times 10^{-11}$ \\
\hline 30 & 20.6 & 1.70 & $5.37 \times 10^{-12}$ \\
\hline 30 & 20.6 & 1.70 & $8.70 \times 10^{-12}$ \\
\hline 30 & 20.1 & 1.72 & $2.56 \times 10^{-12}$ \\
\hline 30 & 20.1 & 1.72 & $3.08 \times 10^{-12}$ \\
\hline 30 & 19.5 & 1.74 & $5.12 \times 10^{-12}$ \\
\hline 30 & 19.5 & 1.74 & $4.74 \times 10^{-12}$ \\
\hline 30 & 20.0 & 1.72 & $4.35 \times 10^{-12}$ \\
\hline 30 & 20.0 & 1.72 & $3.84 \times 10^{-12}$ \\
\hline 30 & 20.2 & 1.72 & $4.10 \times 10^{-12}$ \\
\hline 30 & 20.2 & 1.72 & $3.59 \times 10^{-12}$ \\
\hline 30 & 19.4 & 1.74 & $4.87 \times 10^{-12}$ \\
\hline 30 & 19.4 & 1.74 & $5.00 \times 10^{-12}$ \\
\hline 30 & 19.1 & 1.73 & $3.24 \times 10^{-12}$ \\
\hline 30 & 18.8 & 1.75 & $2.49 \times 10^{-12}$ \\
\hline 30 & 19.2 & 1.74 & $1.89 \times 10^{-12}$ \\
\hline 30 & 19.1 & 1.74 & $3.58 \times 10^{-12}$ \\
\hline 30 & 18.9 & 1.74 & $5.26 \times 10^{-12}$ \\
\hline 30 & 18.7 & 1.75 & $3.94 \times 10^{-12}$ \\
\hline
\end{tabular}


a Ca-type bentonite produced by Kunimine Industries Co. Ltd. The test method also uses falling head permeability test method, as in this study. Specimen conditions in the study [3] are presented in Table 3: the bentonite contents were $15-40 \%$; the initial moisture content was $9-25 \%$; and the dry density was $1.5-2.0 \mathrm{~g} / \mathrm{cm}^{3}$.

From both figures, we can find that hydraulic conductivity tends to decrease as both the effective montmorillonite density and the effective montmorillonite wet density increase. Particularly in Fig. 9, the plot distribution tends to be different for each initial saturation degree of the specimen. In Fig. 10, the plot is distributed on the same correlation irrespective of the initial saturation. The effective montmorillonite density did not incorporate consideration of the mechanism of permeation phenomena inferred as described above. Such a difference appeared in the correlation for each initial saturation level.

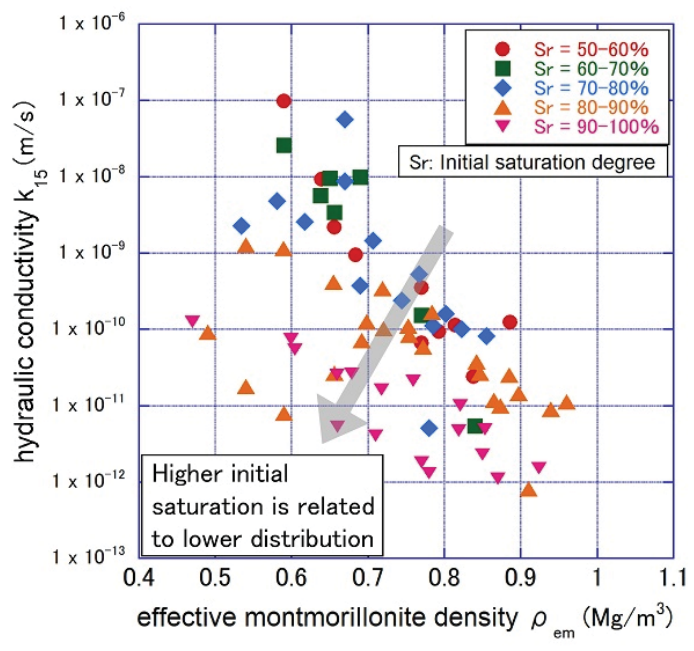

Fig. 9. Relation between hydraulic conductivity and the effective montmorillonite density of Ca-type bentonite mixed soil (legend: initial saturation).

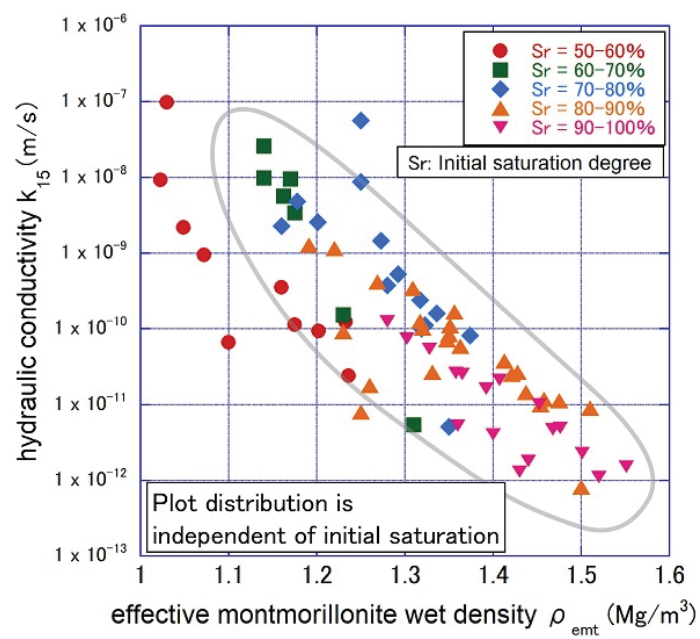

Fig. 10. Relation between hydraulic conductivity and the effective montmorillonite wet density of Ca-type bentonite mixed soil (legend: initial degree of saturation).

\section{Conclusion}

Regarding the hydraulic conductivity of Ca-type bentonite mixed soil, higher initial moisture contents of specimens, higher initial dry density, and higher initial saturation of the specimen indicate more pores with small diameters distributed in the saturated specimen or a smaller gap volume. The hydraulic conductivity is expected to decrease accordingly.

The effective montmorillonite density, which was proposed originally as a substitute index for hydraulic conductivity of bentonite-mixed soil, does not incorporate the initial moisture content of the specimen. As described herein, we proposed the effective montmorillonite wet density considering the initial pore water mass.

Examination of test results for the effective montmorillonite density and effective montmorillonite wet density showed higher correlation of data irrespective of the initial saturation. This result supports the inferred mechanism.

Some of the present work was performed as activities of the Research Institute of Sustainable Future Society, Waseda Research Institute for Science and Engineering, Waseda University.

\section{References}

1. Japan Atomic Energy Society, Construction method of soil cover and facility management method for low-level radioactive waste burial site: Japan Atomic Energy Society standard 2016 pit disposal and trench disposal, AESJ (2016).

2. S. Yokoyama, K. Nakamura, Y. Tanaka, M. Hironaga, Alteration behavior of bentonite barrier of radioactive waste disposal by alkaline solutions -part 2- - Effect of type of alkaline solution on permeability of compacted bentonite-sand mixture, Civil Engineering Research Laboratory, Rep.No.N10037, (2011) (in Japanese).

3. M. Chijimatsu, M. Kimura, H. Ishihama, Effect of mixing method of Ca-type bentonite mixed soil on quality, JSCE, 68, CS11-014, pp. 27-2 (2013) (in Japanese).

4. Japanese Industrial Standard, JIS Z 2451 (2019).

5. H. Komine, Theoretical equations on hydraulic conductivities of bentonite based buffer and backfill for underground disposal of radioactive wastes, ASCE, 134, No. 4, pp.497-508 (2008).

6. H. Komine, Theoretical equations for evaluating hydraulic conductivities of bentonite-based buffer and backfill. Proceedings of the 16th International Conference on Soil Mechanics and Geotechnical Engineering, 4, pp. 22892292 (2005).

7. Research report on utilization of low permeable soil materials and performance evaluation technology, JGS, pp. 47-50 (2016)

8. F. Tatsuoka, K. Fujishiro, K. Tateyama, S. Kawabe, Y. Kikuchi, Properties of compacted soil as a function of dry density and the degree of saturation, The 15th Asian Regional Conference on Soil Mechanics and Geotechnical Engineering, 2, Issue 4, pp. 247-252 (2016).

9. R. Kitamura, K. Sako, Mechanical properties of unsaturated soils - Application to slope stability analysis , Proceedings of the Seventh Symposium on Sediment Disaster, pp. 43-48 (2014) (in Japanese). 